\title{
Abordagens de Gênero e Sexualidade na Psicologia: Revendo Conceitos, Repensando Práticas
}

\author{
Approaches to Gender and Sexuality in Psychology: \\ Reviewing Concepts, Reviewing Practices \\ Abordajes de Género y Sexualidad en la Psicologia: \\ Revendo Conceptos, Recapacitando Prácticas
}

Lenise Santana Borges, Alice de Alencar Arraes Canuto, Danielle Pontes de Oliveira \& Renatha Pinheiro Vaz

Pontifícia Universidade Católica de Goiás

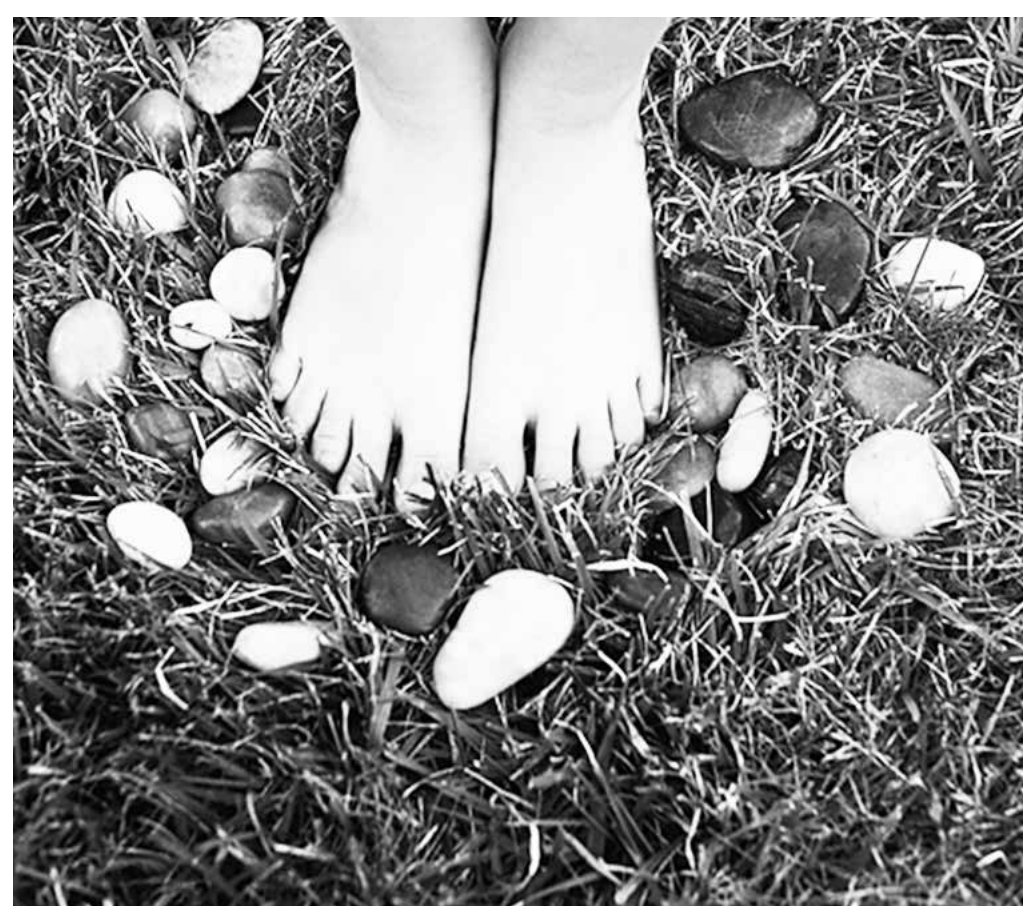


Resumo: Este artigo explora os sentidos sobre gênero e sexualidades a partir da análise das produções acadêmicas dos programas de graduação e pós-graduação do Curso de Psicologia da PUC/Goiás. A partir de uma análise discursiva que tem como enquadre epistemológico o construcionismo social e as teorias feministas, a pesquisa investiga as produções que contenham no título os indexadores: gênero, sexualidade, homossexualidade e/ou homossexual(is), no período de 1993 a 2008. A escolha dessa investigação se dá em razão de que tais produções constituem fontes privilegiadas de informação e de formação. Locais de (re)produção de saber, as universidades operam muitas vezes como lugares que se outorgam o estatuto de verdade, prescrevendo formas morais de comportamento aos sujeitos, o que tem instigado estudiosos/ as a investigar os discursos que circulam no meio acadêmico. Analisam-se, neste estudo, as perspectivas teóricas privilegiadas na descrição do objeto, as áreas e os temas centrais bem como os avanços e as lacunas da produção acadêmica, tomando como contraponto a proposta curricular oferecida pelo curso. Dessa forma, é possível concluir que, no contexto de produção acadêmica analisado, o ensino da Psicologia ainda se concentra predominantemente nos estudos das identidades, em uma visão normativa, polarizada e patologizada quanto ao gênero e às sexualidades.

Palavras-chave: Psicologia. Construcionismo social. Gênero. Sexualidade. Homossexualidade.

Abstract: This article explores the meanings of gender and sexuality from the analysis of academic productions in the programs of undergraduation and graduation from psychology students of PUC/ Goiás. Based on discourse analysis and as epistemology social constructionism combined with feminist theories, the research investigates the production contained in the title indexes: gender, sexuality, homosexuality and/ or homosexual(s) in the period 1993 to 2008. The reason for this choice is due to the fact that productions are privileged sources of information and formation. The universities, as places of knowledge reproduction, often operate as sources that plead the status of truth, prescribing moral forms of behavior to subjects, what has prompted scholars to investigate the discourses that circulate in the academic circles. The theoretical perspectives privileged in the description of the object, the central areas and themes are analyzed in this study, as well as the advances and shortcomings of academic production, which are taken as opposed to the proposal offered by the course curriculum. Thus, we conclude that in the context of the academic production analyzed, the teaching of psychology has focused predominantly on studies of identities in a normative, polarized and pathologized vision of gender and sexualities.

Keywords: Psychology. Social constructionism. Gender. Sexuality. Homosexuality.

Resumen: Este artículo explota los sentidos sobre género y sexualidad a partir del análisis de las producciones académicas de los programas de graduación y pos graduación del Curso de Psicología de la PUC/Goiás. Desde un análisis discursivo que tiene como encuadre epistemológico el construccionismo social y las teorías feministas, la investigación es sobre las producciones que contengan en el título los indexadores: género, sexualidad, homosexualidad y/o homosexual(es), en el período de 1993 a 2008. La elección de esa investigación se da en razón de que tales producciones constituyen fuentes privilegiadas de información y de formación. Lugares de (re)producción de saber cómo las universidades operan muchas veces como lugares que se otorgan el estatuto de verdad, prescribiéndoles formas morales de comportamiento a los sujetos, lo que ha incitado estudiosos/as a investigar los discursos que circulan en el medio académico. Se analizan, en este estudio, las perspectivas teóricas privilegiadas en la descripción del objeto, las áreas y los temas centrales así como los avances y los vacíos de la producción académica, tomando como contrapunto la propuesta curricular ofrecida por el curso. De esa forma, es posible concluir que, en el contexto de producción académica analizado, la enseñanza de la Psicología aún se concentra predominantemente en los estudios de las identidades, en una visión normativa, polarizada y patologizada en relación al género y a las sexualidades.

Palabras clave: Psicología. Construccionismo social. Género. Sexualidad. Homosexualidad.

$\mathrm{Na}$ era moderna, pesquisadores/as das ciências humanas, sobretudo da Psicologia, tornam-se importantes articuladores/as para a formulação e a disseminação de discursos sobre gênero e sexualidades. Muito dessa produção discursiva foi influenciada pelas ciências médicas e sexológicas, as quais, por sua vez, privilegiavam aspectos descritivos dos comportamentos sexuais e, com frequência, apresentavam conclusões de tendência normativa e disciplinar. 
Locais de (re)produção de saber, as universidades operam muitas vezes como lugares que se outorgam o estatuto de verdade, prescrevendo formas morais de comportamento aos sujeitos, o que tem instigado estudiosos/as a investigar os discursos que circulam no meio acadêmico. Frente às rápidas e intensas transformações que o mundo está passando, o campo de estudos sobre gênero e sexualidades têm se tornado central para o cultivo de uma formação acadêmica que inclua as temáticas das desigualdades e da diversidade, sobretudo para a Psicologia, que vem sendo convocada a pensar sobre a questão das assimetrias entre os sexos.

Para a realização de nossa pesquisa, partimos de algumas propostas de investigação interessadas em discutir a formação acadêmica no que se refere a gênero e sexualidade: Citeli (2005), que realizou uma revisão crítica dos estudos sobre sexualidade no Brasil no período de 1990-2002, Maués (2007), que explora a produção acadêmica sobre gênero no contexto nacional, mais especificamente, em Belém do Pará, no período de 1995-2006, Narvaz (2009), que discute a produção acadêmica sobre gênero no contexto da Universidade Federal do Rio Grande do Sul (UFRGS), mais especificamente, do Instituto de Psicologia no período de 1973 a 2008, e Nuernberg (2005), que busca analisar a inserção dos estudos de gênero no campo da produção acadêmica em Psicologia no período de 1980 a 1990.

Em consonância com a compreensão de que os estudos de gênero e sexualidades se situam em um campo interdisciplinar, tornase imperativo para a Psicologia refletir sobre a própria produção acadêmica, traduzida de forma resumida na seguinte indagação: como a Psicologia tem absorvido as noções de gênero e sexualidades no dia a dia da prática do ensino e da pesquisa?
Esta pesquisa se propõe a explorar as noções sobre gênero e sexualidades que circulam na produção acadêmica (trabalhos de conclusão de curso e dissertações de mestrado) do Curso de Psicologia da PUC de Goiás, no período de 1993 a $2008^{1}$.

Desse modo, tal investigação contempla as seguintes perguntas: (1) como tais temáticas vêm sendo utilizadas na produção acadêmica no curso de Psicologia da PUC/GO?, (2) quais noções sobre gênero e sexualidades são centrais nas análises?, (3) gênero articulase a outros marcadores sociais como classe, orientação sexual, raça/etnia, geração, etc.?, (4) que concepções metodológicas e teóricas são privilegiadas na descrição, problematização e análise dos objetos pesquisados?

O interesse por analisar os discursos que circulam no campo acadêmico justifica-se pelo fato de que os discursos produzidos nesse contexto específico, mais do que um lugar de difusão de conhecimento, são dotados da capacidade de constituir o próprio campo discursivo, efetuando versões, redefinições e omissões sobre o que ele transporta. Como destaca Foucault (2004, p.55), discursos são práticas que sistematicamente "formam os objetos de que falam", e não se reduzem a um conjunto de signos que remetem a conteúdos ou a representações.

Entendemos que as diversas possibilidades de atuação profissional no campo da Psicologia pesquisa, formação e intervenção - requerem um investimento contínuo na qualificação profissional para o enfrentamento das desigualdades sociais, quer sejam elas diferenças de classe, sexo, raça/etnia, geração, quer sejam de orientação sexual, só para citar algumas. A incorporação de uma ótica de gênero pode ser entendida como um dos grandes desafios que a Psicologia tradicional tem enfrentado, na medida em que ele exige, de um campo eminentemente neutro 
Na postura pós-moderna, destaca-se a perspectiva construcionista social, que é antiessencialista e antirrealista, e que pressupõe que o mundo social e os indivíduos sejam produtos de um processo social e que não existam essências dentro das coisas/

pessoas que as tornem o que são (Nogueira, 2001b). e disciplinar, um posicionamento político e um olhar interdisciplinar.

\section{Discursos sobre gênero na Psicologia}

A construção do discurso sobre gênero na Psicologia é bastante heterogênea, sendo permeada por distintos posicionamentos epistemológicos. Segundo as indicações da filósofa Sandra Harding (1986) e da psicóloga feminista Conceição Nogueira (2001a), no domínio dos estudos do gênero na Psicologia, destacam-se dois tipos principais de posturas epistemológicas: a perspectiva empiricista, baseada nas abordagens essencialista e de socialização, e a pós-moderna, baseada na abordagem construcionista.

Centrado na abordagem essencialista, o paradigma das diferenças sexuais que orientou a Psicologia na primeira metade do século XX e que constitui a postura empiricista sugere a existência de diferenças inatas e estáveis entre os sexos. Na visão essencialista, gênero é concebido como uma propriedade estável, inata e bipolar de diferenciação sexual, como um caráter eminentemente determinista e como um traço que descreve as personalidades e os processos cognitivos. Nessa mesma postura, mas tendo por base a abordagem da socialização, gênero é entendido como o resultado de forças sociais e culturais, no qual o mesmo é aprendido, e não, inato. A diferença entre homens e mulheres passa a ser explicada não mais pela teoria das diferenças sexuais, mas, primeiramente, pela androginia, e, posteriormente, pela teoria dos papéis sociais, na qual homens e mulheres aprendem e internalizam identidades específicas através da socialização. Um dos problemas da postura empiricista que tem por base a socialização refere-se ao fato de que gênero permanece definido em termos de diferença dicotômica, e continua a ser visto como interno e imutável. Na postura pós-moderna, destaca-se a perspectiva construcionista social, que é antiessencialista e antirrealista, e que pressupõe que o mundo social e os indivíduos sejam produtos de um processo social e que não existam essências dentro das coisas/pessoas que as tornem o que são (Nogueira, 2001b).

Narvaz também apresenta reflexões importantes sobre a utilização do conceito de gênero na produção acadêmica, bem como das reverberações dessa discussão no âmbito da Psicologia. Na sua tese de doutorado, a autora discute as diferentes filiações teóricoepistemológicas vinculadas ao gênero, com algumas possibilidades de concepção:

\section{Aparece ora como característica da identidade individual, ora como uma relação interpessoal; pode ser tanto um modo de organização social quanto uma estrutura da consciência, uma psique triangulada ou uma ideologia internalizada, gênero também, figura quer como categoria de análise de relações de poder manifestas na dominação e subordinação, quer como diferença sexual, ou, ainda, para referir-se a papéis e estereótipos sexuais (2009, pp. 22-23)}

Uma das preocupações dessa pesquisa é que disciplinas como Psicologia, Sociologia, Antropologia, Medicina, História, Direito, etc., têm discursos próprios e podem produzir efeitos perniciosos como a naturalização e o reforço do binarismo de gênero, a vitimização e a culpabilização das mulheres como, por exemplo, nos casos de violência. Nuernberg avalia que o encontro da Psicologia com os estudos de gênero, além de desafiante, produz efeitos vantajosos para a Psicologia, pois exige que essa ciência se desloque do que é familiar/disciplinar/conhecido e busque caminhos menos domesticados, expressão utilizada por Azerêdo (2011), para construirmos uma trajetória que prime pela intensificação do diálogo interdisciplinar. 


\section{Perspectivas teóricas sobre sexualidade: do essencialismo ao construcionismo e ao queer}

Duas perspectivas têm sido identificadas como as mais proeminentes nos estudos sobre sexualidade: essencialismo e construcionismo (Borges, 2009). A primeira busca a ideia de que existe uma natureza essencial produzida dentro dos corpos, que um impulso inato aos indivíduos os leva à ação sexual. Segundo Gayle Rubin (1975), nessa perspectiva, o sexo é considerado uma força natural, pulsional, que existe anteriormente à vida social, inerente aos hormônios ou à psique, sem determinantes sociais significativos.

Já a concepção construcionista problematiza a universalidade de um suposto impulso sexual, uma vez que não existe um saber pré-discursivo; o conhecimento só pode ser produzido através da linguagem. Operar com a perspectiva construcionista significa tanto opor-se à ideia de naturalização do feminino e do masculino como também ser crítica de uma sexualidade rígida, fixa, pelos determinantes biológicos (Borges, 2009).

Uma das referências mais importantes para o pensamento construcionista é a obra clássica de Michel Foucault (1988), autor que afirma ser a sexualidade um constructo até então visto sob a ótica da repressão. Na perspectiva de Foucault, a sexualidade é social e historicamente construída, ou seja, depende da cultura e das relações sociais estabelecidas, o que possibilita pensar em diferentes formas de viver e de construir identidades de gênero e sexuais. A contribuição teórica do autor é inestimável também para entender que a homossexualidade, da mesma forma, é social e historicamente construída, o que possibilita pensar em diferentes formas de viver e de construir identidades de gênero e sexuais. $\mathrm{O}$ homossexual é uma construção sociohistórica e não universalmente aplicável, portanto, requer uma explicação sobre os processos envolvidos em sua construção.
Em meados de 1990, outra perspectiva ganha espaço: a perspectiva queer. Judith Butler, autora feminista, conhecida por ser uma das fundadoras desse movimento, propõe uma leitura do sexo como efeito tanto do processo de naturalização e da estrutura social de gênero como da matriz heterossexual ${ }^{2}$.

Esse movimento se colocou contra tudo aquilo que considerou essencialistas, que tomavam a diferença sexual como uma verdade natural ou pré-discursiva e, finalmente, contra quaisquer imposições normativas de formas determinadas de masculinidade e feminilidade (Prado \& Machado, 2008, pp. 54)

De um modo geral, as teorias queer questionam a posição do sujeito moderno como um todo, em que se considera não apenas os sujeitos gays/lésbicas, a população LGBT, mas também todos/as aqueles/as que se consideram dissidentes das formas normativas. Uma pessoa que se considera heterossexual, mas não quer o matrimônio, ou ter filhos/as, por exemplo, pode ser alguém que, de certo modo, desfamiliarize as concepções normalizadoras de identidade sexual, as relações dominantes de família. Com o conceito queer, portanto, há um deslocamento na ênfase em se considerar a centralidade das identidades sexuais para se considerar as práticas sexuais abrigadas sob o guarda-chuva dos diferentes.

Ao compararmos o ponto de vista construcionista com o queer, podemos afirmar que se, por um lado, a perspectiva construcionista sobre a sexualidade propiciou maior alcance para contestar a naturalização dos sexos a partir da emergência do conceito de gênero, por outro lado, ao não problematizar que o sexo também é construído socialmente, incorporando na discussão a constituição dos corpos, ela não conseguiu romper a ideia de entidades polarizadas e fixas - homens e mulheres, 
3 Tal questão dispunha das seguintes afirmativas: "A contemporaneidade é o cenário no qual novos elementos despontam e convocam posicionamentos subjetivos. É

nesse palco que a homossexualidade e a homofobia devem ser vistas e focalizadas, tanto teórica quanto pragmaticamente.

PORQUE (grifo do texto original) autores como Bauman (1998)

e Jameson (1997)

voltam-se para as

transformações sociais como deflagradoras de mudanças subjetivas: fragmentação, superficialidade, heterogeneidade discursiva e espacialização do tempo e fim da unidade e da centralidade típicos da organização subjetiva da modernidade" (Cremasco et al., 2009, adaptado). A partir dessa leitura, foi perguntado:

"Analisando-se essas afirmações, é correto afirmar que: A) a primeira afirmação é falsa, e a segunda é verdadeira; B) a primeira afirmação é verdadeira, e a segunda é falsa; C) as duas afirmações são falsas; D) as duas afirmações são verdadeiras, e a segunda é uma justificativa correta da primeira; E) as duas afirmações são verdadeiras, mas a segunda não é uma justificativa correta da primeira".

4 Esta autora compreende o feminismo como um movimento social, não homogêneo, de luta das mulheres por igualdade de direitos civis, econômicos, sociais e políticos. homossexualidade e heterossexualidade. A teoria queer diferencia-se da perspectiva construcionista na medida em que radicaliza o questionamento de estabilidade, da fixidez e da coerência das identidades sexuais, representando uma ruptura com as teorias que compreendiam a identidade como algo fixo, coerente e natural (Butler, 2003).

Como podemos perceber, o debate da sexualidade e suas relações com as vertentes essencialista, construcionista e queer vem passando por transformações conceituais e práticas que afetam diretamente a Psicologia. Um dos exemplos práticos de como essas teorizações impactam a formação acadêmica dos estudantes de Psicologia pode ser verificada no enunciado que compõe a pergunta 24 do Exame Nacional de Desempenho de Estudantes (ENADE) $(2009)^{3}$, que exige que o/a aluno/a de Psicologia relacione as transformações sociais e os impactos na subjetividade na discussão contemporânea da homossexualidade e da homofobia.

Vale ressaltar que muitas das mudanças em curso confirmam a importância de alguns movimentos sociais como os movimentos feminista ${ }^{4}$ homossexual $^{5}$, e, mais recentemente, o movimento LGBT, apontados como impulsionadores das transformações nas formas de se conceber as sexualidades bem como da ação estratégica de focalizar as violências contra a homossexualidade (Borges, 2012).

Da teoria à prática psicológica, e em diferentes teorias $p \mathrm{si}^{6}$, articulam-se e arbitram-se possibilidades de existência e marcações de diferenças, controlando corpos, prazeres, desejos e relações, legitimando assimetrias e desigualdades. As teorias proeminentes da Psicologia ocupam um lugar de destaque na produção do saber sobre as (homo) sexualidades, conferindo a essa um valor central. As análises da produção acadêmica também funcionam como uma intervenção na vida política e social, e aí as teorias psicológicas (se) fazem políticas, queiramos ou não (Narvaz, 2009). Se pensarmos que as práticas discursivas que circulam nos cursos de Psicologia contribuem decisivamente para conformar ideias e produzir efeitos sobre pessoas e coisas e que essas práticas têm implicação direta na formação e na prática dos(as) psicólogos(as), torna-se importante e urgente refletir sobre as possibilidade e os limites dos currículos vigentes nos cursos de Psicologia.

Nesse sentido, este estudo é importante tanto do ponto de vista acadêmico, ao avaliar a formação dos estudantes de Psicologia, quanto do campo de atuação e das práticas com as quais esses estudantes estarão se deparando, confirmando a necessidade ainda de se proceder a investigações sobre os discursos que transitam no curso de Psicologia.

\section{Referencial teórico e metodológico da pesquisa}

Esta pesquisa se ancora no arcabouço teórico metodológico do construcionismo social (Ibáñez, 1994; Spink, 2004; Iñíguez, 2002) e nas interpretações contemporâneas para o gênero a partir dos estudos feministas e queer (Nogueira, 2001a, 2001b; Butler, 1993, 2003). A postura construcionista, aliada a uma leitura feminista, permite compreender a produção do conhecimento como algo construído mediante determinadas práticas humanas, na qual os discursos e a linguagem empregados variam segundo os contextos social e histórico específicos. Trata-se, portanto, de um estudo documental exploratório qualitativo, cujo foco de análise são as práticas discursivas e os sentidos, entendidos como linguagem em ação, sempre múltiplas, situadas e dialógicas. A produção acadêmica do Curso de Psicologia da PUC/GO é compreendida como documentos de domínio público e 
analisada segundo conceitos da abordagem de análise das práticas discursivas. Segundo Peter Spink (2000, p.136), os documentos de domínio público são "produtos sociais tornados públicos", e carregam, por meio de sua publicização, distintas versões de formas de pensamento advogadas ou assumidas por um grupo específico. Arquivos diversos, diários oficiais e registros, jornais e revistas, anúncios, publicidade, manuais de instrução e relatórios são alguns exemplos que podem ser analisados pela metodologia das práticas discursivas.

O termo práticas discursivas refere-se à linguagem em uso, em movimento, e inclui tanto os aspectos performáticos como as condições de sua produção (Spink, 2004); são entendidas como linguagem em ação, maneiras pelas quais as pessoas produzem sentidos e se posicionam em relações sociais cotidianas, incluindo, em sua composição, a dinâmica, isto é, os enunciados orientados por vozes, pelas formas, conhecidos por speech genres ou gêneros de fala, formas relativamente estáveis de enunciados que buscam coerência com o tempo, o contexto, e o(s)/a(s) interlocutor(es)/(as) e pelos conteúdos que são os repertórios interpretativos. Estes, segundo Spink (2004), são o conjunto de termos, lugares-comuns e descrições usadas em construções gramaticais e estilísticas específicas.

\section{Método}

5 Movimento social que centra suas lutas especificamente nas reivindicações da população homossexual.

6 Psi refere-se não somente a Psicologia mas também aos campos da psicanálise e da psiquiatria.
O corpus da pesquisa é composto por trabalhos de conclusão de curso, dissertações do curso de Psicologia da Pontifícia Universidade Católica de Goiás, no período de 1993 a 2008, período que marca a expansão dos estudos de gênero e no Brasil. A escolha para iniciar a pesquisa nessa universidade justificase por ter sido essa a primeira universidade a oferecer o curso de Psicologia no Estado, e por ser a única até o momento a oferecer curso de graduação e pós-graduação: mestrado, desde 1999, e doutorado, desde $2007^{7}$.

Os procedimentos metodológicos foram:

1. Identificação das produções acadêmicas que contivessem em seu título o indexador gênero, sexualidade, homossexualidade e/ou homossexual(is);

2. Mapeamento do conteúdo dessas produções acadêmicas;

3. Descrição das concepções teóricas e metodológicas das produções;

4. Busca pela proposta curricular do Curso de Psicologia da PUC-GO, no intuito de identificar se há alguma alusão a gênero e/ou a sexualidades;

5. Análise das concepções descritas conforme os objetivos propostos.

\section{Procedimentos de coleta de dados}

Os trabalhos de conclusão de curso (TCC) foram selecionados a partir do banco de dados do Centro de Estudos, Pesquisa e Prática Psicológica (CEPSI). A busca por trabalhos com o indexador gênero ocorreu de duas maneiras: no período de 1993 a 2005, por meio de uma seleção manual, e, a partir de 2005, por meio de listas, já com a catalogação dos trabalhos, o que facilitou a seleção.

A partir dessa primeira etapa de seleção, realizamos uma primeira leitura integral de cada TCC. Os dados obtidos subsidiaram a elaboração de um quadro geral contendo: título da produção, palavras-chave, ano, área e referencial teórico. Em uma segunda etapa, extraímos trechos relacionados ao indexador propostos para serem analisados detalhadamente, o que resultou em um segundo quadro, com as seguintes informações do trabalho: 1) resumo, 2) metodologia, 3) conclusão, e 4) três colunas com trechos dos trabalhos, que contemplassem (a) a 
compreensão do conceito, (c) os referenciais teóricos e (d) as referências bibliográficas.

As dissertações de mestrado do programa de pós-graduação stricto sensu encontramse digitalizadas e disponíveis, a partir de 2004, na biblioteca on line da PUC/GO, e as anteriores a 2004 foram consultadas na Biblioteca Central da PUC/GO. A busca na pós-graduação seguiu os mesmos procedimentos adotados na graduação, resultando também em dois quadros para análise das dissertações de mestrado. As teses de doutorado não foram incluídas, pois, no período proposto para análise, ainda não haviam sido terminadas.

Após as etapas de seleção dos trabalhos e dos trechos relevantes, foi elaborado um terceiro quadro com a identificação dos repertórios e dos sentidos mais recorrentes a partir das citações, repertórios, sentidos, autores/as e referenciais teóricos.

\section{O Curso de Psicologia na PUC/ GO: proposta curricular}

O Curso de Psicologia da PUC/Goiás teve origem no Departamento de Educação; foi implantado em agosto de 1973, mas só foi reconhecido pelo Ministério de Educação e Cultura-MEC em 1978. Vale a pena salientar que ele é o primeiro curso no Estado de Goiás, e manteve-se como única opção por mais de duas décadas.

O programa, na graduação, possui duas ênfases: a) ênfase em processos psicossociais: Psicologia escolar e educacional, Psicologia social e Psicologia das organizações e do trabalho, b) ênfase em processos de avaliação, clínicos e de saúde: psicologia hospitalar e da saúde, clínica em comportamental, clínica em Gestalt, clínica em psicodrama e clínica em psicanálise. Atualmente, a Matriz Curricular da Graduação (2006/2) é constituída por 10 períodos, totalizando 262 créditos, e guarda variação aproximada entre 20 a 30 créditos em cada período. Desses 262 créditos, 206 estão na grade curricular obrigatória, e 56 créditos se dispõem como ênfase optativa ao aluno/a. Dos créditos obrigatórios, 44 indicam ênfase na Psicologia social e nos processos culturais, e os outros 162 indicam ênfase nas teorias da personalidade, processos psicodiagnósticos, avaliações e métodos, psicopatologias e Psicologia clínica.

O Programa de Pós-Graduação Stricto Sensu em Psicologia (PSSP) da PUC/GO foi implantado em 1999 com o curso de mestrado, e, em 2007, teve início o curso de doutorado. O programa abriga três linhas de pesquisa: 1) análise e evolução do comportamento, 2) Psicologia social, do trabalho e das organizações e 3) psicopatologia clínica e Psicologia da saúde. A grade de disciplinas do PSSP conta com 02 disciplinas obrigatórias e 29 disciplinas optativas segundo a linha de pesquisa escolhida.

\section{Gênero e sexualidades na proposta curricular}

A partir desse levantamento da proposta curricular da Psicologia, buscamos disciplinas na graduação e na pós-graduação que indicassem a inclusão de estudos que abarcassem, como proposta, estudos sobre sexualidades e gênero. Em nossa busca, foi encontrada uma disciplina optativa na graduação, disponível a partir do primeiro semestre de 2011: Psicanálise e Gênero, (PSI1530), cuja proposta de ementa afirma explicitamente trabalhar com gênero. $\mathrm{Na}$ ementa, consta que a disciplina tem por objetivo estudar "o processo de feminilidade, em um recorte de gênero, por meio dos teóricos Freud, Lacan e outros psicanalistas contemporâneos". Todavia, sabe-se que existem disciplinas que tangenciam a discussão de gênero e sexualidade, como Psicologia Social I, Psicologia Social II, Psicologia Social III, Processos Culturais e Políticas Públicas. 
Na pós-graduação, a temática de gênero comparece em duas disciplinas optativas ligadas à linha da Psicologia social: Tópicos Especiais em Psicologia Social: Análise de Conteúdo/Construcionismo, oferecida no primeiro semestre de 2011, e Temas de Pesquisa em Processos Psicossociais: Práticas Discursivas e Produção de Sentidos, oferecida no segundo semestre de 2011.

\section{Resultados/discussão}

Identificamos, na graduação, um total de 3.377 produções acadêmicas, e, na pós-graduação, um total de 181 dissertações. Dessa amostra, foram selecionadas para análise aquelas produções que continham pelo menos um dos indexadores no título: gênero, sexualidade, homossexualidade, homossexual e/ou homossexuais. Caso houvesse mais de um indexador, procedíamos à leitura do documento por inteiro para selecionar o indexador que era mais central na discussão.

Das 3.377 (100\%) produções da graduação, encontramos 63 (1,8\%) produções com pelo menos um dos indexadores no título, sendo 15 (0,4\%) com o indexador gênero, 31 (1\%) com o indexador sexualidade, e 17 (0,5\%) com o indexador homossexualidade.

Tabela 1. Quantidade de produções com os indexadores gênero, sexualidade e homossexualidade mantidas e excluídas para análise na graduação

\begin{tabular}{lcc}
\hline Indexadores & Mantidos & Excluídos \\
\hline Gênero & $15(0,4 \%)$ & $3.362(99,6 \%)$ \\
Sexualidade & $31(1 \%)$ & $3.346(99 \%)$ \\
Homossexualidade & $17(0,5 \%)$ & $3.360(99,5 \%)$ \\
\hline
\end{tabular}

Na pós-graduação, das 181 dissertações (100\%), encontramos 09 (4,9\%) produções com pelo menos um dos indexadores, sendo 03 (1,6\%) com o indexador gênero, 03 (1,6\%) com o indexador sexualidade e $03(1,6 \%)$ com o indexador homossexualidade.

Tabela 2. Quantidade de produções com os indexadores gênero, sexualidade e homossexualidade mantidas e excluídas para análise na pós-graduação

\begin{tabular}{lcc}
\hline Indexadores & Mantidos & Excluídos \\
\hline Gênero & $03(1,6 \%)$ & $178(98,4 \%)$ \\
Sexualidade & $03(1,6 \%)$ & $178(98,4 \%)$ \\
Homossexualidade & $03(1,6 \%)$ & $178(98,4 \%)$ \\
\hline
\end{tabular}

Esses resultados demonstram que as temáticas de gênero e sexualidades permanecem na periferia do campo de interesses no Curso de Psicologia da PUC/GO, embora, mais recentemente, se perceba algumas iniciativas tanto na graduação e na pós-graduação em viabilizar tais discussões, como, por exemplo, a criação de algumas disciplinas cujas ementas indicam explicitamente a discussão desses temas. Uma explicação possível para essa falta de interesse do Curso de Psicologia em relação a essas temáticas é apresentada por Azerêdo (2011), no seu artigo Encrenca de Gênero nas Teorizações em Psicologia. Na experiência como professora, Azerêdo reflete sobre a dificuldade vivida por alguns alunos/as de ter que se deparar com a complexidade do conceito de gênero bem 
como com a necessidade de considerar, para suas análises, os processos de subjetivação juntamente a análises cuja ênfase recai sobre o político. Os resultados aproximam-se de outras pesquisas, como as de Nuernberg e Narvaz, que mostram que a temática de gênero permanece marginal no campo de estudos da Psicologia. Se pensarmos que a Psicologia, nas suas raízes e movimentações teóricas, permanece ainda muito colada ao ideário modernista, reiterando uma série de pensamentos individualistas e essencialistas, coloca-se presente a intrincada e lenta entrada das análises que contemplam a perspectiva feminista e/ou de gênero. Quando há a tentativa de se abrir para outras discussões como o debate de gênero, isso é feito desde que ele apareça de forma subjacente e sustentada por análises baseadas em categorias e dualismos, como sexo versus gênero, semelhança versus diferença (Nogueira, 2001a), dentre outros.

No que se refere às temáticas da sexualidade e da homossexualidade, nota-se que, apesar de haver maior número de trabalhos, o teor das discussões tende a aproximar-se mais de leituras essencialistas e biologizantes, embora se perceba um processo de deslocamento para leituras mais construcionistas, sobretudo nos trabalhos situados na área da Psicologia social, especialmente na pós-graduação.

Outro resultado que chama a atenção é que não há registro de produção com o indexador gênero no título no período de 1993 até 2000, aparecendo somente a partir de 2001 e seguindo uma frequência constante até 2008. Já no que se refere à sexualidade, a primeira produção na graduação aparece em 1995, e, a partir daí, o tema se mantém constante, com uma intensificação no período de 2003 e 2004. Na homossexualidade, as primeiras produções aparecem em 1998, e há uma continuidade com pelo menos um trabalho nos anos subsequentes até 2008 .
Na pós-graduação, as produções acadêmicas (dissertações de mestrado) apresentam uma distribuição mais esparsa, e incorporam o indexador gênero nas suas produções a partir do ano 2003, a homossexualidade, em 2004, e a sexualidade, em 2005. Apesar de os programas de graduação e de pósgraduação terem tempos de existência diferenciados, enquanto a graduação tem início no ano 1963, o mestrado data do ano 1999, com as primeiras dissertações do programa defendidas no ano 2001. Notase, proporcionalmente, participação maior das temáticas de gênero e sexualidade e homossexualidade na pós-graduação.

\section{Áreas, referenciais teóricos, temas e repertórios na graduação}

As produções na graduação se distribuem nas seguintes áreas: clínica, social/organizacional e saúde/hospitalar. Nas produções acadêmicas cujo indexador é gênero, 53,3\% dos trabalhos situam-se na área organizacional, e 46,7\%, na clínica. No que se refere ao indexador sexualidade, 49\% localizam-se na clínica, $32 \%$, na saúde/hospitalar, e 19\%, na social, e, no indexador homossexualidade, $100 \%$ das produções situam-se na área clínica.

Uma tendência verificada é que a maior parte dos trabalhos cujos indexadores são sexualidade ou homossexualidade se situam na área clínica e da saúde, com uma forte inclinação a práticas intervencionistas, com ênfase em referenciais teóricos da Psicologia clínica, médica e sexológica.

No que se refere aos referenciais teóricos utilizados para o indexador gênero, temos: $26,7 \%$ na fenomenologia e na Psicologia sistêmica, 20\% na psicanálise, e 13,3\% na comportamental e na psicodinâmica. Para a sexualidade: $39 \%$ na Psicologia da saúde/hospitalar, 29\% na psicanálise, 
$26 \%$ na fenomenologia e 3\% na comportamental e nas teorias do desenvolvimento. Para a homossexualidade: $47 \%$ na psicanálise, $23 \%$ na comportamental, $18 \%$ no psicodrama e $12 \%$ na fenomenologia.

Os temas relativos a gênero se configuram em dois eixos: na área organizacional, enfatizam-se as relações entre homens e mulheres no contexto de trabalho, e, na área clínica, na escolha de parceiros/as e relacionamentos interpessoais. Na sexualidade, os temas referem-se à vivência individual, às etapas do desenvolvimento da sexualidade, à sexualidade e aos procedimentos cirúrgicos, a doenças como câncer e AIDS, sexualidade na terceira idade e no período gestacional, à questão do abuso sexual, à sexualidade na infância e na adolescência, e à sexualidade feminina. Na homossexualidade, o tema mais recorrente é a identidade do sujeito homossexual, referida geralmente como um problema no desenvolvimento identitário e como uma questão da personalidade.

Do ponto de vista da condução das discussões, nota-se que, tanto para o gênero quanto para as sexualidades, prevalece uma discussão baseada em acepções fixas sobre as identidades sexuais. Gayle Rubin (1975) chama a atenção para o fato de que é possível falar das sexualidades como uma constitucionalidade fundamental nos sujeitos e referi-la a termos essencialistas, mas, dessa forma, ela fica inacessível à análise política se for discutida primariamente como um fenômeno biológico ou como um aspecto da psicologia individual. Pensando nas possíveis relações entre a história da Psicologia e a construção de noções sobre as (homo)sexualidades, nota-se ainda o peso de algumas tendências hegemônicas como a sexologia e a psicanálise, que continuam marcando de forma inequívoca o campo psi.

Na tabela abaixo, listamos os principais repertórios para gênero, sexualidade e homossexualidade utilizadas no contexto dos referenciais teóricos adotados:

Tabela 3. Repertórios sobre gênero, sexualidade e homossexualidade a partir dos respectivos referenciais teóricos na graduação

\begin{tabular}{|c|c|c|}
\hline Indexadores & Referencial teórico & Repertórios utilizados \\
\hline \multirow[t]{5}{*}{ Gênero } & Fenomenologia & $\begin{array}{l}\text { Masculinidade e feminilidade; configuração psicológica que combina e } \\
\text { integra identidade pessoal e sexo biológico; forma de dar significado a } \\
\text { relações de poder. }\end{array}$ \\
\hline & Sistêmica & $\begin{array}{l}\text { Masculino e feminino; categoria de análise para explicar as diferenças } \\
\text { entre os sexos; formas de construção que diferenciam mulheres e } \\
\text { homens; papéis que desempenham socialmente. }\end{array}$ \\
\hline & Psicanálise & $\begin{array}{l}\text { Aspectos psíquicos da organização masculina e feminina; graus de } \\
\text { masculinidade e feminilidade; configuração psicológica que combina } \\
\text { identidade pessoal e sexo biológico. }\end{array}$ \\
\hline & Comportamental & $\begin{array}{l}\text { Diferenças socialmente impostas entre papéis masculinos e femininos; } \\
\text { relações entre homens e mulheres na sociedade. }\end{array}$ \\
\hline & Psicodinâmica & $\begin{array}{l}\text { Característica socialmente construída a partir do componente biológico } \\
\text { que diferencia homens e mulheres; principal } \\
\text { elemento organizador das relações sociais. }\end{array}$ \\
\hline
\end{tabular}




\begin{tabular}{|c|c|c|}
\hline Indexadores & Referencial teórico & Repertórios utilizados \\
\hline \multirow[t]{5}{*}{ Sexualidade } & $\begin{array}{l}\text { Saúde/ } \\
\text { hospitalar }\end{array}$ & $\begin{array}{l}\text { Papéis sexuais, feminino ou masculino; instinto biológico voltado para a } \\
\text { reprodução da espécie; parte natural da vida; conjunto de excitações e } \\
\text { atividades ligado ao coito; parte integrante da personalidade; característica } \\
\text { da identidade. }\end{array}$ \\
\hline & Psicanálise & $\begin{array}{l}\text { Um instinto, comportamento pré-formado, característico da espécie; } \\
\text { a própria essência da atividade humana; todas as expressões da vida } \\
\text { fundadas no sexo. }\end{array}$ \\
\hline & Fenomenologia & $\begin{array}{l}\text { Conjunto de fenômenos da vida sexual e social; energia pulsional; } \\
\text { maneira de ser e estar no mundo. }\end{array}$ \\
\hline & Comportamental & Não apresenta definição da sexualidade. \\
\hline & $\begin{array}{l}\text { Teorias do } \\
\text { desenvolvimento }\end{array}$ & $\begin{array}{l}\text { Não se reduz aos atos genitais, inclui todas as demonstrações de afeto, } \\
\text { como beijos, abraços e carinho; não se limita ao sexo. }\end{array}$ \\
\hline \multirow[t]{4}{*}{ Homossexualidade } & Psicanálise & $\begin{array}{l}\text { Escolha objetal; narcisismo; suspensão do desenvolvimento psicossexual; } \\
\text { desenvolvimento libidinal sofre alguma perturbação. }\end{array}$ \\
\hline & Comportamental & $\begin{array}{l}\text { Determinada pela experiência sexual iniciada; possibilidade de estímulos } \\
\text { aversivos; variante natural da sexualidade humana. }\end{array}$ \\
\hline & Psicodrama & $\begin{array}{l}\text { Síndrome homossexual; preferência sexual em ser ativo ou passivo; } \\
\text { imagem perdida de si mesmo. }\end{array}$ \\
\hline & Fenomenologia & $\begin{array}{l}\text { Aqueles que têm como objeto de amor e desejo um outro homem; não se } \\
\text { trata da uma opção sexual; a homossexualidade não é uma escolha. }\end{array}$ \\
\hline
\end{tabular}

Os repertórios indicam a incorporação da temática de gênero que tem como ênfase a questão da identidade sexual erigida a partir de um substrato biológico determinante. Percebe-se, nos trabalhos, uma assimilação do discurso de gênero, ainda que limitado a noções que mantêm intactos alguns sentidos que versam sobre dualismos, como cultura versus natureza.

Ressalta-se também a pouca ou nenhuma articulação desse marcador de diferença com outros marcadores como: classe, raça, geração, sexualidade e orientação sexual, entre outros. Talvez uma das explicações para essa discussão ainda incipiente de gênero na graduação seja a escolha preferencial de autores/as de uma linhagem que é consonante unicamente com o contexto da abordagem teórica privilegiada. Sendo assim, mesmo que o tema requeira uma abordagem interdisciplinar, os trabalhos se limitam a buscar citações dentro do referencial teórico adotado. No que se refere aos repertórios para conceitualizar a sexualidade, percebe-se uma polissemia de definições. No entanto, nota-se a predominância de noções que se aproximam de uma vertente que concebe a sexualidade como algo inato e natural. Outro aspecto que chama a atenção é a ocorrência da não conceitualização de sexualidade em vários trabalhos, tomando-a como um conceito previamente definido.

\section{Áreas, referenciais teóricos, temas e repertórios na pós-graduação}

Na pós-graduação, as produções referentes a gênero e sexualidades situam-se basicamente na área social/organizacional. No que se refere aos referenciais teóricos utilizados para o indexador gênero, temos: 33,3\% na Psicologia evolucionista, 33,3\% na psicodinâmica e 33,3\% na psicossocial. Para a sexualidade, 33,3\% na fenomenologia, 33,3\% na psicanálise e 33,3\% na Psicologia sociohistórica. 
Os referenciais adotados para discutir homossexualidade aparecem unicamente no contexto da abordagem psicossocial.

Os temas relativos a gênero referem-se ao comportamento social e a relações de gênero e trabalho. Na sexualidade, referem-se à sexualidade feminina, à terceira idade e à violência, $\mathrm{e}$, na homossexualidade, os temas deslocam-se para a análise do preconceito contra homossexuais na área do ensino, dos recursos humanos e da adoção de crianças por casais homossexuais. É notável, na pós-graduação, um processo de deslocamento para leituras mais construcionistas, sobretudo na área da Psicologia social.

Tabela 4. Repertórios sobre gênero, sexualidade e homossexualidade a partir dos respectivos referenciais teóricos na pós-graduação

\begin{tabular}{|c|c|c|}
\hline Indexadores & Referencial teórico & Repertórios utilizados \\
\hline \multirow[t]{3}{*}{ Gênero } & Evolucionista & Não apresenta definição de gênero. \\
\hline & Psicodinâmica & $\begin{array}{l}\text { Masculinidade e feminilidade; relações sociais fundadas sobre } \\
\text { diferenças percebidas entre os sexos; relações de poder; } \\
\text { produto social aprendido, em que o poder que permeia tal } \\
\text { relação é desigualmente distribuído; categorias biológicas de } \\
\text { machos ou fêmeas tornam-se categorias sociais de mulheres e } \\
\text { homens; construção social. }\end{array}$ \\
\hline & Psicossocial & Papéis sociais: masculino e feminino. \\
\hline \multirow[t]{3}{*}{ Sexualidade } & Fenomenologia & Não apresenta definição da sexualidade. \\
\hline & Psicanálise & $\begin{array}{l}\text { As culturas sexuais do século XIX exemplificam o caráter } \\
\text { socialmente construído da sexualidade; as relações entre } \\
\text { homens e mulheres, ao longo dos séculos, mantêm caráter } \\
\text { excludente, pois são assimiladas de forma bipolarizada, } \\
\text { designando à mulher a condição de inferior. }\end{array}$ \\
\hline & Sócio-histórica & $\begin{array}{l}\text { A sexualidade pode ser percebida como processo dinâmico; } \\
\text { a sexualidade do ser humano não se restringe ao enfoque } \\
\text { puramente de procriação; a sexualidade não é unívoca, } \\
\text { mas constituída por uma pluralidade de tendências e de } \\
\text { atividades. }\end{array}$ \\
\hline Homossexualidade & Psicossocial & $\begin{array}{l}\text { Vários fatores que fazem com que uma pessoa se descreva } \\
\text { como homossexual; variedade de influências; interações } \\
\text { entre o indivíduo e o ambiente social; movimentos sociais; } \\
\text { mudanças econômicas, formação de ações coletivas em torno } \\
\text { do tema; homossexualidade, uma orientação sexual sem } \\
\text { causas específicas. }\end{array}$ \\
\hline
\end{tabular}

Percebe-se, na pós-graduação, a utilização de repertórios que transitam por diferentes acepções sobre o conceito de gênero, sobressaindo a noção de gênero como papéis sociais. No que se refere à sexualidade, há uma tentativa de articular gênero e sexualidade bem como de discutir a sexualidade no contexto de uma visão mais construcionista. Na homossexualidade, as discussões tomam um caráter mais interacionista e social, envolvendo uma leitura mais diversificada e ampla sobre o tema. 
Se tomarmos os resultados da graduação e da pós-graduação comparativamente, poderemos notar maior abertura na pósgraduação para incorporar as temáticas de gênero, sexualidade e homossexualidade, com uma tendência a maior interdisciplinaridade na discussão. Já na graduação, prevalece uma tendência à escassez de trabalhos, especialmente sobre a temática de gênero, bem como uma discussão menos plural. Tal constatação pode ser considerada algo da própria natureza da graduação, com sua inclinação a seguir uma linha mais tradicional, disciplinar, quase escolástica. Já a pós-graduação e sua natural vinculação com a pesquisa exige uma produção acadêmica mais vinculada às problemáticas lançadas pelos campos empíricos.

\section{Revendo conceitos, repensando práticas}

Os resultados mostram que as produções acadêmicas constituem uma produção discursiva múltipla e polissêmica na qual coexistem discursos mais institucionalizados, denominados tempo longo, na linguagem das práticas discursivas, e discursos de tempo curto, mais próximos dos discursos que circulam na atualidade (Spink,2000).

Assuntos como direitos humanos, direitos sexuais e políticas públicas não podem estar fora no escopo de temas para a Psicologia. Eles devem ser referência para uma formação integral e crítica do/a profissional da área. No entanto, mais do que uma preocupação pura e simples com o conteúdo, é preciso estar sintonizado com as necessidades atuais do mundo, que possibilitam a criação de projetos e de práticas inovadoras que respondam a essas demandas.

Embora o estudo se limite a um recorte da produção acadêmica, representados especificamente pelos programas de graduação e pós-graduação da Psicologia da PUC/Goiás - em função de decisões metodológicas como viabilidade e acesso ao banco de dados dessa universidade -, esperase que esta pesquisa possa provocar uma reflexão sobre a produção teórica e prática do ensino em Psicologia.

Uma das possibilidades de romper esse ciclo de reprodução de discursos que naturalizam as desigualdades é fazermos uso da reflexividade, como propõe a postura construcionista, revendo internamente conceitos, práticas e possíveis efeitos da produção acadêmica, em especial a produção oriunda do campo psi. Estudos que têm o objetivo de buscar refletir sobre o tipo de conhecimento que tem sido produzido pela Psicologia parecemnos um caminho importante no sentido de desestabilizar noções e regras rígidas e aparentemente fixas, que tomam como verdades determinadas versões sobre o masculino e o feminino e as sexualidades.

Tais versões, uma vez naturalizadas, dão forma aos conhecimentos ensinados e aprendidos na Universidade, compondo o arsenal explicativo, ou seja, as possibilidades consideradas legítimas ou não de os sujeitos viverem seus desejos, corpos, sexualidades, etc., e que trazem profundos efeitos nas práticas profissionais dos futuros/as psicólogos/ as nos campos da clínica, do trabalho, do ensino, da pesquisa, das políticas públicas, da família, etc.

Nesse sentido, acreditamos ser necessária a ampliação de estudos como este para outras universidades brasileiras sobre as temáticas de gênero e sexualidades, bem como a diversificação das estratégias metodológicas. Propomos ainda, como recomendação, a transversalização da perspectiva de gênero como uma ação que alcance as diversas 
possibilidades de ensino que o curso de Psicologia oferece: ensino, extensão, pesquisa. Tal transversalização deveria estar contida nas diversas ênfases do currículo de Psicologia - Processos Psicossociais e Processos de Avaliação, Clínico e de Saúde - tendo como referência discussões teóricas e metodológicas sobre gênero e suas articulações com as políticas públicas. Em função das lacunas detectadas nesta pesquisa, como também na pesquisa de Narvaz, seria importante que o curso incorporasse leituras sobre os processos psíquicos a partir de uma leitura de gênero, sobretudo no campo da clínica.

Lenise Santana Borges

Doutora em Psicologia Social pela Pontifícia Universidade Católica de São Paulo e docente da Pontifícia Universidade

Católica de Goiás, Goiânia - GO - Brasil.

E-mail: esinel@uol.com.br

Alice de Alencar Arraes Canuto

Psicóloga formada pela Pontifícia Universidade Católica de Goiás, Goiânia- GO - Brasil.

E-mail: aliceaacanuto@gmail.com

Danielle Pontes de Oliveira

Psicóloga formada pela Pontifícia Universidade Católica de Goiás, Goiânia- GO - Brasil.

E-mail: danpontes.psi@gmail.com

Renatha Pinheiro Vaz

Psicóloga formada pela Pontifícia Universidade Católica de Goiás, Goiânia- GO - Brasil.

E-mail: nathinha87@hotmail.com

Endereço para envio de correspondência:

PUC de Goiás, Departamento de Psicologia,. Avenida Universitária, 1440, Setor Universitário. CEP: 74605-010. Goiânia, GO. 


\section{Referências}

Azerêdo, S. (2011). Encrenca de gênero nas teorizações em psicologia. Estudos Feministas, 18(1), 175-188.

Bauman, Z. (1998). O mal estar na pós-modernidade. Rio de Janeiro: Jorge Zahar.

Borges, L. (2009). (Homo)sexualidades e formação profissional: desafios para a psicologia. Revista Eletrônica de Psicologia e Políticas Públicas, 1(1), 146-157.

Borges, L. (2012). Políticas públicas, movimento LGBT e a psicologia: diálogos e tensões de um campo em construção. In J. Chaves (Org.), Psicologia social e políticas públicas: contribuições e controvérsias. Goiânia, GO: Editora da PUC Goiás.

Butler, J. (1993). Bodies that matter. On the discursive limits of "sex". New York/London: Routledge.

Butler, J. (2003). Problemas de gênero: feminismo e subversão da identidade. Rio de Janeiro: Civilização Brasileira.

Citeli, M. T. (2005). A pesquisa sobre sexualidade e direitos sexuais no Brasil (1990-2002): revisão crítica. Rio de Janeiro: CEPESC.

Cremasco, M. V. \& Thielen, I. P. (2009). Brokeback Mountain e o segredo de todos nós: subjetividades na contemporaneidade. Cadernos de Pesquisa Interdisciplinar em Ciências Humanas, 10(96), 68-81.

Exame Nacional de Desempenho de Estudantes. (2009). Prova psicologia. Recuperado em 08 agosto, 2012, de http:// enade.unifra.br/wp-content/uploads/2012/03/PROVA PSICOLOGIA.pdf

Foucault, M. (1988). História da sexualidade. I. A vontade de saber. Rio de Janeiro: Graal.

Foucault, M. (2004). A arqueologia do saber. Rio de Janeiro: Forense Universitária.

Harding, S. (1986). The Science Question in Feminism. Ithaca: Cornell Univ. Press.

Ibáñez, T. (1994). Psicologia social construcionista. Guadalajara: Universidade de Guadalajara.

Íñiguez, L. (2002). Construcionismo social e psicologia social. In J. B. Martins (Org.), Temas em análise institucional e em construcionismo social. São Carlos, SP: RIMA.
Jameson, F. (1997). Pós-modernismo: a lógica cultural do capitalismo tardio. São Paulo: Ática.

Maués, M. (2007). A temática gênero nas produções provenientes dos grupos de pesquisa da Universidade Federal do Pará. (Dissertação de Mestrado). Programa de Pós-Graduação em Educação. Universidade Federal do Pará, Belém, PA.

Narvaz, M. (2009). A (in)visibilidade do gênero na psicologia acadêmica: onde os discursos fazem(se) política. (Tese de Doutorado). Programa de Pós-Graduação em Psicologia. Universidade Federal do Rio Grande do Sul, Porto Alegre, RS

Nogueira, C. (2001a). Feminismo e discurso do gênero na psicologia social. Psicologia \& Sociedade, 3(1), 107-128.

Nogueira, C. (2001b). Contribuições do construcionismo social a uma nova psicologia do gênero. Cadernos de Pesquisa, $112,137-153$

Nuernberg, A. (2005). Gênero no contexto da produção científica brasileira. (Tese de Doutorado). Programa de Pós-Graduação Interdisciplinar em Ciências Humanas. Centro de Filosofia e Ciências Humanas da Universidade Federal de Santa Catarina, Florianópolis, SC.

Prado, M., \& Machado, F. (2008). Preconceitos contra homossexualidades: a hierarquia da invisibilidade. São Paulo: Ed. Cortez. (Col. Preconceitos, 5).

Rubin, G. (1975). Pensando o sexo: notas para uma teoria radical das políticas da sexualidade. (F. B. Martins Fernandes, trad. M. Pillar Grossi, rev.). Recuperado em 02 ago., 2012, http:// www.miriamgrossi.cfh.prof.ufsc.br/pdf/gaylerubin.pdf.

Spink, M. (2000). Práticas discursivas e produção de sentidos no cotidiano: aproximações teóricas e metodológicas. São Paulo: Cortez.

Spink, M. (2004). Linguagem e produção de sentidos no cotidiano. Porto Alegre: EDIPUCRS.

Spink, P. (2000). Análise de documentos de domínio público. In M. J. Spink (Org.), Práticas discursivas e produção de sentidos no cotidiano: aproximações teóricas e metodológicas. São Paulo: Cortez. 